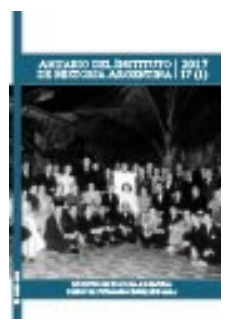

Anuario del Instituto de Historia Argentina, vol. 17, nº 1, e040, junio 2017.

ISSN 2314-257X

Universidad Nacional de La Plata.

Facultad de Humanidades y Ciencias de la Educación.

Centro de Historia Argentina y Americana

\title{
El Partido Socialista y su delimitación con el movimiento anticlerical en los primeros años del siglo XX
}

\author{
The Socialist Party and its Delimitation with the Anti-Clerical \\ Movement in the First Years of the Twentieth Century
}

\section{Lucas Poy *}

* Instituto de Historia Argentina y Americana Dr. Emilio Ravignani - CONICET Universidad de Buenos Aires, Argentina | lucaspoy@gmail.com

\section{PALABRAS CLAVE}

Partido Socialista

Alfredo Palacios

Juan B. Justo

Anticlericalismo

Liberalismo

\section{KEYWORDS}

Socialist Party

Alfredo Palacios

Juan B. Justo

Anticlericalism

Liberalism

\section{RESUMEN}

El objetivo del artículo es analizar los debates que en los primeros años del siglo XX se desarrollaron en el interior del Partido Socialista argentino en torno al modo de intervención en el movimiento anticlerical. En particular, examina la polémica que se trabó entre Alfredo Palacios y la dirección partidaria, a propósito de la creación de los llamados “círculos de obreros liberales”. El artículo reconstruye estos debates, hasta ahora inexplorados por la historiografía, a través de un examen de la prensa socialista y anticlerical del período. La investigación argumenta que, si bien el Partido Socialista otorgó un lugar destacado a las denuncias contra el clero y fue parte activa del movimiento anticlerical, desarrolló al mismo tiempo una delimitación con otros sectores del mismo 


\section{Introducción}

En Argentina, los primeros años del siglo XX estuvieron marcados por una creciente tensión política y social. Luego de la retracción que había tenido lugar entre 1897 y 1899, la recuperación económica dio lugar a un ascenso de la conflictividad obrera, que derivó en la declaración de la primera huelga general de la historia del país, en noviembre de 1902, y la violenta respuesta represiva del gobierno que incluyó la sanción de la ley 4.144, conocida como de Residencia. En esos años también se vivió un proceso de tensiones diplomáticas con Chile, en el marco del cual se desarrollaron movilizaciones callejeras con consignas nacionalistas; a mediados de 1901, una serie de manifestaciones con importante presencia estudiantil rechazó un acuerdo de renegociación de la deuda suscripto por el gobierno en Europa, logrando finalmente su anulación y dando lugar a una ruptura entre Julio A. Roca y Carlos Pellegrini que tendría serias consecuencias para el régimen político en los años posteriores (Marotta, 1960; Oved, 1976; Korzeniewicz, 1989; Rock, 2006; Rojkind, 2006; Castro, 2012).

En este contexto, otro importante eje de conflicto durante el período fue el proceso de movilización y debate público que enfrentó a sectores conservadores vinculados a la Iglesia Católica con un amplio y heterogéneo conjunto de grupos anticlericales y "librepensadores". El debate era producto del nuevo escenario del país, caracterizado por la consolidación de la construcción estatal iniciada décadas antes, la profundización de la integración económica con la economía mundial, y el surgimiento de tensiones sociales y políticas derivadas de la aparición de un joven pero pujante movimiento obrero. Si en la década de 1880 se había aprobado una serie de reformas legislativas -vinculadas con la educación, el matrimonio y el registro civil, la secularización de los cementerios, etc.- que recortaron el poder de la Iglesia Católica, en el contexto del cambio de siglo la resistencia del clero comenzaba a evidenciar una mayor receptividad de parte de la clase política, preocupada por garantizar el orden.

En 1900, el diputado Carlos Olivera presentó un proyecto de ley de divorcio que, en los años sucesivos, generó un proceso de debate público y polarizó las opiniones fuera y dentro del congreso, donde la Iglesia articuló un bloque de opositores al proyecto en torno al diputado y obispo Gregorio Romero. En 1902, finalmente, el proyecto fue rechazado en la Cámara de Diputados -si bien por apenas dos votos-, lo que otorgó una importante victoria al sector clerical opuesto a los cambios. Como ha señalado Lilia Bertoni (2009), el episodio marcó "un claro límite al desarrollo de la laicidad y [constituyó] un momento de significativa inflexión en el poder de la Iglesia para arbitrar en asuntos civiles y públicos”. Para que este cambio fuera posible fue decisivo el rol de Roca, que en su segundo gobierno mostró un interés creciente por acercarse al clero. Pero también la propia intervención de la Iglesia, que libró "fuertes disputas en diarios y revistas, en el Congreso y también en las calles, por cuyo dominio rivalizó con demostraciones masivas" (2009, p. 45).

Las discusiones y el proceso de delimitación política que examinamos en este artículo deben ubicarse en este contexto de confrontación pública. Tal como destacó Roberto Di Stefano, los debates de estos años "estuvieron enmarcados en un clima de intolerancia, de denuncia, de combate, que contribuyó a construir las imágenes de campos enfrentados e irreconciliables en la política y en la sociedad” (2010, p. 252). Las presiones de la Iglesia en el ámbito legislativo, en la prensa y en las movilizaciones callejeras se vieron enfrentadas por un conjunto de acciones que nuclearon a aquellos partidarios de reformas liberales. Este movimiento anticlerical estaba caracterizado por una fuerte heterogeneidad: era una corriente de pensamiento amplia, expresada en diversos tipos de publicaciones y organizaciones, que incluía a masones y protestantes, a socialistas y anarquistas, a republicanos y liberales. Sus diferencias no eran menores, pero los unificaba su defensa de la laicidad, la libertad de pensamiento y un común rechazo a la Iglesia y a la influencia del clero en la sociedad. La compartida identidad anticlerical, según caracteriza Di Stefano, permitió "crear un terreno lo suficientemente amplio como para permitir el diálogo y la acción común de 
esas corrientes a veces incompatibles y la confluencia de hombres y mujeres provenientes de diferentes estratos sociales y medios culturales” (2010, pp. 297-298). Para construirse en oposición a la Iglesia y a sus prácticas, el movimiento anticlerical tenía "sus propios rituales, como los matrimonios y entierros civiles", sus conferencias y congresos, sus "peregrinaciones a lugares de culto laico, como el monumento a Garibaldi y la plaza Roma” y hasta "un calendario que ritmaba la vida de los devotos en torno a grandes gestas de la lucha anticlerical” (2010, pp. 296-297).

La heterogeneidad del movimiento anticlerical se veía reforzada por el hecho de que atravesaba a distintas fuerzas políticas: en torno a este tipo de debates, en efecto, solían quebrarse lealtades partidarias o de facción y se articulaban bandos a través de otras líneas, tal como pudo observarse en la reñida votación sobre el proyecto de ley de divorcio. Una excepción, en este sentido, la constituía el Partido Socialista, que si bien en esta etapa carecía de representación parlamentaria era la única fuerza política que se colocaba de un modo coherente y homogéneo en el campo anticlerical. Tal como señala Dévrig Mollès, "las afinidades entre el PS y librepensamiento eran evidentes", en tanto su propio programa "contemplaba la separación de la Iglesia y del Estado y sus estatutos prohibían a los afiliados contraer matrimonio religioso” (2012, p. 255). Además de estos planteamientos programáticos y estatutarios, el socialismo local otorgó un lugar muy destacado e insistente a las denuncias contra el clero y por ello no resulta sorprendente que sus militantes y dirigentes fueran una parte activa del movimiento anticlerical del período.

Esta constatación, de todas formas, no hace sino plantear otro interrogante: ¿cuáles eran las particularidades del vínculo que, en la práctica, se estableció entre el Partido Socialista y el más amplio movimiento anticlerical? ¿Cuál debía ser la relación entre ambos? ¿Qué grados de autonomía era preciso mantener? Como veremos, la resolución del problema no fue sencilla: si bien es indiscutible que el socialismo argentino desarrolló una clara identidad anticlerical y que, en un sentido general, desenvolvía una interpretación de la sociedad que tenía muchos vasos comunicantes con un pensamiento liberal dominante en la época, la dirección partidaria intentó en forma insistente marcar sus distancias organizativas y políticas con el resto del movimiento anticlerical. Estas tensiones se expresaron de una manera definida en torno a una discusión que se desarrolló en los años 1901-1902 y enfrentó a casi toda la dirección partidaria con el recientemente incorporado Alfredo Palacios. 1

El objetivo de este artículo es reconstruir estos debates y explicitar el papel que jugaron los mismos en el contexto más general de un partido que se esforzaba por construir una delimitación política con otras fuerzas “progresistas" para así justificar y conquistar un espacio propio en el escenario político de la Argentina de comienzos del siglo XX. Con ese fin, trabajamos en forma extensa con La Vanguardia, el periódico oficial del Partido Socialista, así como con otras publicaciones anticlericales del período, además de basarnos en informaciones publicadas por la prensa comercial.

\section{Los socialistas frente al movimiento anticlerical: frente común y delimitación}

Los socialistas argentinos compartían algunos planteos fundamentales sobre la cuestión religiosa y clerical que constituían un acervo común de la socialdemocracia de la época. El artículo quinto del programa de Erfurt, aprobado en 1891 por la socialdemocracia alemana, planteaba que las corporaciones eclesiásticas debían considerarse "como sociedades privadas, arreglando sus propios asuntos con plena autonomía”ㄹ. Esto habilitaba dos planteos complementarios que formaban la base de los posicionamientos socialistas en el período: por un lado, el reclamo de separación de la iglesia y el estado, anulación de cualquier aporte presupuestario y recuperación de los bienes cedidos al clero; por el otro, la posibilidad de interpelar a los trabajadores que profesaban una religión e incorporarlos a las filas socialistas, concediendo que sus creencias religiosas eran un asunto privado. La "separación de la Iglesia y el Estado” y la “abolición del presupuesto 
del clero y confiscación de sus bienes" figuraban textualmente en el primer programa de los socialistas argentinos, elaborado a principios de 1894 y fueron luego consagrados en el programa mínimo aprobado en el congreso constituyente de 1896 (Oddone, 1983: p.25 y p. 66).

Más allá de estos acuerdos generales, no obstante, las circunstancias históricas concretas de los diferentes países, el grado de desarrollo tanto del movimiento obrero como del clero y las diversas coyunturas políticas fueron creando escenarios en los cuales los socialistas debían elaborar posicionamientos más precisos, en particular en la medida en que cobraban fuerza movimientos anticlericales de composición social y política heterogénea ${ }^{3}$. Argentina no fue una excepción. Cuando, a fines de 1900 y fundamentalmente durante 1901, se agudizó la tensión entre la Iglesia y el movimiento anticlerical, sobre todo en la ciudad de Buenos Aires, los socialistas dedicaron una atención importante tanto a la elaboración política sobre el tema como a la organización de actividades.

Junto a la campaña por el proyecto de ley de divorcio, la agitación callejera contra los abusos cometidos en el correccional de menores bajo la dirección del padre Pedro Bertrana -que movilizó a amplios sectores de la opinión y terminó con la detención del mismo- fue uno de los detonantes que profundizó la agitación anticlerical y contó con una activa participación de los socialistas (Freidenraij, 2011). El domingo 30 de diciembre de 1900 una manifestación por esta causa fue reprimida por la policía en Plaza Lorea, y varios socialistas, entre ellos Guido Cartei, el editor del periódico, fueron detenidos. Apenas unos días más tarde, La Vanguardia dedicó una editorial firmada por el propio Cartei a denunciar "la reacción clerical” y trazar una caracterización al respecto. La nota se concentraba en los abusos de Bertrana pero iba más allá y argumentaba que la obra del clero era “continua, enérgica y constante” y que podía advertirse su avance "en los poderes públicos, en las escuelas, en los establecimientos penitenciarios, en los decretos presidenciales, en todas partes”. Esta influencia de la Iglesia constituía "un peligro cada vez más grande para el progreso social, la cultura del pueblo, la paz de las familias y la libertad de los ciudadanos”. La caracterización de Cartei se insertaba sin dificultad en las interpretaciones socialistas de la época, en tanto consideraba que la persistencia de estos elementos reaccionarios no era sino un producto de "la grave depravación de las costumbres públicas y privadas" y, sobre todo, de "la miseria intelectual y moral de la burguesía argentina, la más vil y baja de todas las burguesías”. La conclusión era que los socialistas no podían mirar "con indiferencia la actual reacción católica, sino hacer una activa campaña contra ella” y planteaba la necesidad de la unidad con todos los sectores anticlericales. Según La Vanguardia, "todos, socialistas y hombres de progreso”, debían unir sus fuerzas "en esta lucha para que el enemigo quede derrotado cuanto más antes”. 4

Los socialistas, en efecto, participaron activamente en las movilizaciones que se sucedieron en esta etapa. En una nueva movilización realizada contra los abusos de Bertrana, el 13 de enero, participaron como oradores Adrián Patroni, Alfredo Palacios y Nicolás Repetto. En marzo, una representación de Electra de Benito Pérez Galdós - una obra criticada por la Iglesia- dio lugar a manifestaciones anticlericales en Buenos Aires y en otras ciudades del país, en las que nuevamente participaron los socialistas. El 8 de junio, La Vanguardia publicó la crónica de un acto anticlerical realizado en la Boca donde habían participado como oradores Belisario Roldán, Pietro Gori y el propio Palacios. El 15 de septiembre se realizó un mitin convocado por un “comité popular liberal” que reunía a un vasto conjunto de sectores: clubes liberales, grupos masónicos, sociedades gremiales y centros locales del Partido Socialista, además de personalidades independientes. La concentración partió de plaza Once y llegó hasta el congreso, donde se buscaba presentar una petición que reclamaba la separación entre la Iglesia y el estado y la aprobación de un proyecto presentado por Emilio Gouchon, pero esto no pudo hacerse por "encontrarse las oficinas cerradas". Luego la marcha siguió hasta plaza Colón, donde hablaron el dirigente socialista Alfredo Torcelli en nombre del "Centro Liberal de La Plata”, y el "presidente del Comité Popular Liberal, Dr. Alfredo L. Palacios”. Al final de la manifestación 
hubo un choque con la policía, que dejó varios heridos $\underline{5}$.

Dos semanas más tarde, el domingo 29 de septiembre, se realizó una manifestación organizada por los Círculos de Obreros Católicos, luego de haber regresado de una peregrinación a Luján, con el objetivo de rechazar las propuestas del mitin liberal. Una delegación incluso ingresó a la Casa de Gobierno y el presidente les prometió "que haría todo lo posible en favor de los círculos, para incluir, en los asuntos de prórroga del congreso, el proyecto de descanso dominical y reglamentación del trabajo de menores” $\underline{6}$. Sin embargo, la jornada estuvo marcada por los incidentes; según Bertoni, “cuando los peregrinos bajaron de los trenes y comenzaron a encolumnarse para ir a la Plaza de Mayo, fueron silbados e insultados por varios grupos reunidos en plaza Once". A pesar de la intervención policial, "el coche del obispo Romero, los peregrinos y las propias fuerzas policiales fueron apedreados". Más tarde, centenares de personas atacaron la iglesia de la Piedad “a los gritos de “¡Mueran los frailes!”, “¡Abajo el clero!” y “¡abajo la policía que los defiende!” (...) Hubo tiros y manifestantes detenidos” (2009, p. 19).

A pesar de que jugaban un papel protagónico en sus actividades, los socialistas se sentían al mismo tiempo incómodos con el carácter heterogéneo del movimiento anticlerical, en términos de líneas políticas y de clase. Las tensiones se hacían sentir a cada paso, en especial en ocasión de la sucesión de incidentes violentos y, más allá de las apelaciones a realizar acciones conjuntas, a lo largo de 1901 la dirección del Partido Socialista no dejó de poner en evidencia tanto sus reparos ante esta coexistencia política con otros grupos como su intención de dejar clara una delimitación. En este marco, un número creciente de publicaciones de La Vanguardia se dedicaba a polemizar no solo con la Iglesia sino con otros sectores que participaban del movimiento anticlerical.

A fines de mayo, por ejemplo, un artículo de Basilio Vidal salió al cruce de Olivera, el diputado que había presentado el proyecto de ley de divorcio. La actitud contrastaba con la valoración positiva de un año antes, cuando La Vanguardia había publicado amplios extractos de un manifiesto elaborado por el mismo diputado que señalaba que los socialistas "no podían menos que simpatizar" con un proyecto de estas características " $\mathrm{y}$ apoyarlo venga de donde venga, porque lo creemos bueno y justo" $\underline{\underline{ }}$. Ante el crecimiento y desarrollo del movimiento anticlerical, los socialistas creían necesario dejar clara una delimitación. El motivo de la crítica era que Olivera había escrito un artículo en el que planteaba que el socialismo estaba entre sus apoyos, pero luego en la Cámara había planteado que Argentina debía evitar convertirse en España o Portugal, países que rechazaban el divorcio y estaban "carcomidos por el socialismo". Vidal explotaba esta contradicción en la argumentación de su adversario pero, en cualquier caso, el eje de su artículo era subrayar que la del divorcio era una reivindicación que ninguna fuerza política podía reclamar como propia, a excepción de los socialistas que la tenían inscripta en su propio programa desde el congreso fundacional ${ }^{8}$.

Otro ejemplo de esta búsqueda de diferenciación lo encontramos en una nota de fondo publicada a fines de agosto -cuando Nicolás Repetto se había hecho cargo de la redacción del periódico- que polemizaba con Gouchon, otro diputado liberal y masón que se había enfrentado a la Iglesia. La Vanguardia subrayaba la pertenencia de Gouchon a las huestes de la vilipendiada "política criolla", y destacaba que Gouchon integraba "la misma pandilla política que el diputado O’Farrell, clerical patentado”. El artículo remarcaba el peso que aún tenía la religión en el país, y recordaba que el estado sostenía el culto católico y que era necesario pertenecer a esa religión para ejercer ciertos cargos públicos. En línea con los planteamientos del programa erfurtiano, la conclusión subrayaba que, si bien los socialistas eran "respetuosos de las creencias sinceras y tolerantes con las transacciones que en la vida privada imponen a veces las preocupaciones de los demás", se planteaban luchar "para que el Estado no tiranice las conciencias, y no haya en la vida pública más fórmulas morales que las que todo el mundo pueda aceptar; para que no haya iglesia ni secta privilegiada; para que los clérigos, con sotana o sin ella, tengan las mismas obligaciones que los demás 
hombres"

La delimitación incluía también aspectos vinculados a la táctica y la organización. El 7 de septiembre, Esteban Dagnino lamentaba la "apatía” que convertía a muchos anticlericales en "cómplices indirectos" del avance religioso, y advertía a su vez que no eran suficientes los "mitins y conferencias" si ellos no tenían "un método de lucha eficaz y práctico que pueda contrarrestar el avance de la secta clerical”. Para Dagnino, carecía de perspectivas un método que se limitara a acciones puramente declamativas: "mientras nos limitemos a burlarnos de sus farsas”, concluía, “mientras no hagamos algo práctico contra su ponzoñosa propaganda, este monstruo formidable seguirá atravesándosenos en el camino” $\underline{10}$. En la misma línea, un artículo de Juan Domenech publicado una semana más tarde explicitaba una crítica a los convocantes del mitin del 15 de septiembre: su manifiesto, argumentaba, no formulaba "ninguna aspiración concreta" y no era más que "un amontonamiento de frases campanudas y rimbombantes que solo logran confundir a los pacientes lectores” $\underline{11}$.

Las críticas y la delimitación se profundizaron luego de los incidentes callejeros del mes de septiembre. Quien volvió a salir al ruedo fue Cartei, con una nota que tenía el sugestivo título de "Anticlericalismo utópico y anticlericalismo científico" y señalaba que el mitin del 15 de septiembre había fracasado "moral y materialmente”. Cartei lamentaba en primer lugar la baja concurrencia -“la inmensa mayoría de la población bonaerense vio con musulmana indiferencia la iniciativa”-, pero se concentraba sobre todo en delimitarse del método de los organizadores. Cuestionaba que muchos miembros del movimiento confundieran “anticlericalismo con vocinglería” y criticaba explícitamente el método de los “anticlericales burgueses” por ineficaz: según Cartei, estos “organizan un mitin por cada año, echan unos cuantos ¡viva! ¡abajo! y ¡muera!, rompen varios cristales, reciben o reparten algunos coscorrones, y luego... cada uno a su casa, alegre como castañuela”.

La orientación que le imprimían estos "anticlericales burgueses” al movimiento, en suma, soslayaba "el trabajo oscuro, paciente, práctico y sustancial”. En oposición se erigía la propuesta de los socialistas, que era capaz de ofrecer una interpretación de conjunto del fenómeno y una respuesta sistemática y metódica. Cartei recordaba que, para los socialistas, el clericalismo se basaba "en la ignorancia del pueblo y en la de la burguesía, en las instituciones creadas por los católicos para atraer a la muchedumbre, y en el Estado que subvenciona a una iglesia oficial". La ignorancia del pueblo no podía "contrarrestarse sino por medio de escuelas laicas, cursos científicos, conferencias”. Para ganar a los trabajadores debían ofrecer organizaciones sindicales y cooperativas fuertes; para obtener la separación de la Iglesia del estado no debían presentar "peticiones al congreso nacional, representante de una burguesía inepta, atrasada e interesada en la manutención de la iglesia”, sino “ejercitar con amplitud y energía la acción política para llevar a cabo, por medio de legisladores que representen nuestros intereses, una reforma tan trascendental” $\underline{12}$.

El 5 de octubre, Ángel Sesma retomaba los mismos argumentos: “¿Queréis reformar la sociedad a gritos? (...) ¿Queréis convencer a los obreros católicos de que van contra sus intereses, y no halláis mejor medio de hacerlo que llamarles carneros? ¿Queréis extirpar el clericalismo apaleando frailes y gritándoles cuervos?” $\underline{13}$ La crónica de los incidentes, publicada en el mismo número, caracterizaba tanto la acción de los católicos como la de los anticlericales y la policía como una expresión de esa "ignorancia” y falta de cultura política:

Muchos ciudadanos que se la tiran de liberales, guiados por su intolerancia fueron a estorbar la peregrinación de los católicos y armaron bronca. La policía, que no deseaba otra cosa, realizó numerosas prisiones y atropelló de la manera más brutal. Por su parte, los católicos, excitados por los sentimientos de odio que gota a gota ha echado sobre ellos la propaganda corruptora de los Grotte, Martínez y otros frailes, y estimulados por la protección manifiesta de vigilantes, cabos y sargentos, 
secundaron e imitaron a estos llegando a desquitarse hasta con las mujeres y los niños. $\underline{14}$

En suma, los socialistas se manifestaban claramente en favor de participar en las acciones de protesta del movimiento anticlerical pero consideraban necesario marcar, simultáneamente, sus diferencias con la orientación que le imprimían al mismo los “anticlericales burgueses”. La única lucha anticlerical consecuente era la que desarrollaba también una construcción política autónoma de los trabajadores, capaz de enfrentar a la Iglesia y sus defensores más directos, pero también a un régimen político y una clase dominante que eran, en última instancia, los responsables de la expansión del clericalismo. La cuestión anticlerical se insertaba así en el mismo prisma de lectura que caracterizaba a las polémicas de los socialistas con otros adversarios políticos como los anarquistas: se imponía un método gradual, pedagógico y por lo tanto no violento, en contraste con aquel que era incapaz de comprender las causas sociales y económicas del adversario a combatir y, por lo tanto, promovía erupciones violentas sin lograr construir una neta diferenciación política. En esta línea, Cartei criticaba a aquellos "que se dicen anticlericales y son los más energúmenos en las demostraciones callejeras” pero "pertenecen a las pandillas de las que forman parte O’Farrell y monseñor Romero, cuando no son muchachos incorporados a los rebaños mitreros o roquistas, o carbonari que se tragan tres frailes diarios, pero que no sacan la carta de ciudadanía”토.

\section{Alfredo Palacios y su acercamiento al socialismo}

En este marco, Alfredo Palacios comenzaba a perfilarse como una de las figuras clave de esta compleja vinculación entre socialismo y movimiento anticlerical. A pesar de su juventud -Palacios nació en Buenos Aires el 10 de agosto de 1878- su protagonismo y popularidad en el seno de diversos grupos liberales era ya indiscutible, aunque su acercamiento a las filas del socialismo era reciente. En junio de 1900 había tenido lugar la reprobación de su tesis doctoral, titulada "La miseria”, cuando el joven estudiante no había cumplido aún los 22 años. Fue como consecuencia de este rechazo que se trabaron los primeros vínculos entre Palacios y el Partido Socialista: el 4 de agosto Adrián Patroni publicó una nota en La Vanguardia reivindicando la tesis, y por esas fechas apareció también un artículo de Alfredo Torcelli en un diario de La Plata con la misma intención. El 19 de agosto, a partir de una invitación del propio Patroni, Palacios participó como orador en un acto organizado por el centro socialista de la sección norte. En su reseña del acto, La Vanguardia comentaba que se había propuesto a Palacios la incorporación al partido, pero que éste había contestado que no era "menester inscribirse en una agrupación para dar pruebas de convicciones socialistas". $\underline{16}$

Esas líneas anticiparon el desarrollo de los meses posteriores; en términos generales, también prefiguraban la relación siempre compleja que se configuraría entre Palacios y el partido a lo largo de décadas. Desde mediados de 1900, en efecto, Palacios comenzó a participar cada vez con mayor asiduidad en actividades partidarias, a las cuales era invitado como disertante debido a su creciente popularidad, pero no estaba afiliado y se resistía a hacerlo. La dirección del partido se apresuró a emitir señales de alerta: el 22 de septiembre el Concejo Nacional aprobó una resolución que advertía que "tratándose de conferencias socialistas los oradores deben ser personas que militen en el Partido Socialista”, y a fin de año otra del mismo tenor subrayaba que el comité ejecutivo debía valerse, "siempre que sea posible, del concurso de los compañeros afiliados cuando se trate de hacer propaganda estrictamente socialista” $\underline{17}$.

Pero la popularidad de Palacios seguía en ascenso y la situación se extendió durante 1901, una etapa durante la cual, como hemos visto, se multiplicaron las actividades del movimiento anticlerical en las cuales Palacios tenía un rol protagónico. En este contexto, el desagrado de la dirección del partido ante la reticencia de Palacios a sumarse en forma orgánica a las filas socialistas se combinó con -y se vio potenciada por- la creciente preocupación por establecer una delimitación con el resto del movimiento anticlerical. Si los 
socialistas debían intervenir en él con una fisonomía claramente diferenciada, era preciso definir con premura la situación del joven abogado. El 24 de agosto La Vanguardia lamentaba no comprender "por qué el doctor Palacios no se afilia a nuestro partido si encuentra tan bueno su programa” $\underline{18}$.

Ante una situación que se había hecho insostenible, Palacios se incorporó finalmente al centro socialista de La Plata, el 31 de agosto de 1901. En un balance elaborado en 1915, luego de la expulsión de Palacios del partido, Enrique Dickmann señalaba que aquel había tomado esa decisión "después de un año de merodeo por el partido y después de dar a éste bastante dolor de cabeza”. El hecho irregular de que su incorporación hubiera tenido lugar en el centro de la ciudad de La Plata, cuando en realidad Palacios vivía y trabajaba en Buenos Aires, se debía según Dickmann a su “indisposición” con todos los centros socialistas de la capital y a su intención de "sustituirse al contralor, a la crítica y a la censura" de los mismos (García Costa, 1997, p. 88).

En cualquier caso, la incorporación de Palacios no eliminó estos “dolores de cabeza” sino que planteó la discusión en otro plano: en pleno auge del movimiento anticlerical, y en un marco en el cual los socialistas estaban embarcados en un proceso de delimitación con otros sectores del mismo movimiento, la incorporación de una figura como Palacios -un popular e indisciplinado simpatizante del socialismo con gran predicamento entre los círculos liberales- presagiaba un debate abierto. La cuestión de la violencia en las manifestaciones anticlericales actuó como disparador. En una conferencia realizada el 6 de octubre, el joven abogado disertó sobre “ciencia y religión” y dedicó un tramo a cuestionar "a quienes habían criticado los tumultos callejeros" de las manifestaciones de septiembre (García Costa, 1997, p. 90). En el siguiente número de La Vanguardia, un artículo de Bartolomé Bosio cuestionó su defensa de la teosofía y recordó a Palacios que "el socialismo, basándose como lo hace en la ciencia", se oponía a "todo lo que se aparta de la observación y experimentación”. Bosio admitía que había sido "brillante” la crítica a la religión pero lamentaba el apoyo dado por Palacios a esas manifestaciones violentas, negaba que hubieran sido “espontáneas y llevadas a cabo sin premeditación” y recordaba que este tipo de acciones eran "improductivas para la causa que defendemos” y no reflejaban “el método que usa el socialismo” $\underline{19}$.

Palacios envió una respuesta que fue publicada el 19 de octubre: allí se extendía largamente en su defensa de la teosofía y al final reafirmaba su posición sobre los incidentes, "por más resoluciones que emanaran del comité diciendo lo contrario". Palacios argumentaba que ese tipo de disturbios eran criticables si eran "premeditados, organizados, dirigidos", pero que "cuando el pueblo se encontraba en multitud y contestaba la provocación, aunque no fuera directa, de la gendarmería y de los inconscientes, con espontaneidad, hacía bien”. Concluía planteando que "el método evolutivo a que se refiere Bosio" no podía implicar "permanecer en una pasividad deprimente”므. La respuesta de Palacios instaló el debate en La Vanguardia, y la importancia de la discusión quedaría de manifiesto por la amplia lista de dirigentes que intervinieron en la misma.

\section{Los “círculos de obreros liberales” y la polémica de Palacios con la dirección partidaria}

Quien primero salió a la palestra fue Nicolás Repetto, detrás del seudónimo Publisher, para introducir un nuevo elemento en la crítica: la participación de Palacios en la fundación de "círculos de obreros liberales". Se trataba de una iniciativa de algunos sectores del movimiento anticlerical que consideraban que era necesario estructurar este tipo de asociaciones para salir al cruce de los círculos de obreros católicos que desde hacía ya una década eran impulsados por la Iglesia. Según sus estatutos, los círculos tenían por objetivo "promover la unión y el bienestar moral y material de la clase trabajadora” y se planteaban la tarea de organizar "socorro mutuo para los casos de enfermedad", fundar "escuelas primarias para niños y nocturnas para adultos, en las cuales se dará una instrucción sólida y moral”, bibliotecas obreras, agencias de 
trabajo, consultorios médicos y jurídicos, así como celebrar "fiestas y conferencias públicas sobre temas científicos, sociales y morales". Para poder ser miembro se establecía como requisito "no estar afiliado a ninguna sociedad con fines o tendencias contrarias a los de los Círculos de Obreros Liberales”, practicar “alguna industria o profesión honrada” y “observar buena conducta y ser de costumbres morales”ㄹ.

En septiembre de 1901 se había inaugurado el Círculo de Obreros Liberales del Maldonado con la presidencia del espiritista Cosme Mariño, quien había sido uno de los fundadores del diario La Prensa y mantenía una relación de amistad con Palacios (García Costa, 1997, p. 89). La intervención de Repetto tomaba esta inauguración para colocar la discusión en un nuevo escenario. Partía de recordar que el cosmopolitismo de la clase obrera local era un "obstáculo para su organización política y económica”, frente a lo cual el Partido Socialista se había dado a la obra "difícil y laboriosa de instruir sobre sus necesidades comunes a hombres que diferían esencialmente bajo muchos conceptos, y aunarlos para crear una fuerza política”. Ante estos esfuerzos, los intentos de crear círculos de obreros católicos -del mismo modo que la fundación de una "sociedad de obreros israelitas"- jugaban un papel retrógrado. Estas iniciativas, según Repetto, solo retrasaban la tarea decisiva, que era unir a la clase trabajadora en una fuerza política propia. "Si los obreros obran como católicos, liberales o judíos, solo alcanzarán satisfacciones (?) de orden moral: verse agrupados según sus preocupaciones religiosas”르.

La gravedad de la discusión quedó fuera de duda cuando, el 9 de noviembre, intervino el propio Juan B. Justo con una editorial titulada "Socialismo y liberalismo". La larga nota de Justo -que no solía intervenir en forma personal en los diversos debates internos que atravesaban el partido en este período- buscaba colocar la discusión en un plano más general y volcar toda su autoridad política en contra de la postura de Palacios. Comenzaba planteando que reinaba una "grave confusión" respecto al "problema de la relación entre las ideas y la acción política”, criticando así no solo a Palacios sino también la opinión del propio Repetto/Publisher, quien había concluido que "los obreros todos, católicos, liberales, etc., poniendo de lado las divergencias teórico-religiosas, pueden y deben unirse en un partido político”. Según Justo, había que diferenciar distintos niveles de acción común: la unión podía comprenderse, "no solo entre obreros, sino entre personas cualesquiera de ideología diferente, cuando tienen un fin concreto y determinado para cuya realización quieren combinar sus esfuerzos”. Ponía como ejemplo la acción conjunta de los socialistas con otras sociedades, incluidas las católicas, cuando se trataba de iniciar un movimiento por el descanso dominical. Pero el Partido Socialista tenía fines “mucho más amplios y trascendentales”, que iban más allá de la obtención de una u otra reforma particular. Los socialistas admitían "la protección del trabajador por medio de la ley, venga de donde viniere”, pero buscaban ante todo "la emancipación del obrero por su propio esfuerzo, gremial y político”. $\underline{23}$ Sus objetivos eran "la defensa y la elevación del pueblo trabajador”, para lo cual eran "buenos todos los medios, la fuerza, la huelga, el boycott, la cooperación, el voto, cuando son eficaces"르.

Para llevar adelante esta acción, concedía Justo, para que existiera "paz, igualdad y libertad entre los hombres" era necesario hacer desaparecer "la mentira religiosa”. El socialismo estaba por lo tanto interesado en "todo progreso de las ideas en materia religiosa” y miraba "con simpatía los retoños liberales que están apareciendo en este país, aunque sean tardíos y, por el momento, débiles”. Se diferenciaba así de Repetto, cuestionando que el artículo de éste confundiese al liberalismo con una secta y negase "la influencia que la libertad en la crítica y la práctica religiosas tiene en la elevación mental y, como consecuencia, en la elevación material del proletariado”. Justo comparaba al liberalismo, en los países latinos, con el protestantismo en los anglosajones: ambos promovían "la manifestación del libre examen, el juicio autónomo de cada hombre acerca del dogma recibido”. Según su opinión, en este sentido el liberalismo era “el precursor del socialismo”. Pero es aquí donde Justo introducía un nuevo elemento: desde su perspectiva, 
ese carácter progresivo solo podía plantearse en relación con la burguesía:

Si se quiere hacer del liberalismo cuestión de clase, no hay que dirigirse a la clase obrera sino a la clase burguesa. Bajo la bandera liberal ha dado esta sus más grandes batallas contra la rutina y la reacción; y hoy mismo, el liberalismo es el lema de la burguesía que mira hacia adelante.

Ese liberalismo burgués, en la medida en que era progresivo, debía transformarse. No podía limitarse a proclamar los "derechos abstractos del hombre" sino que debía ocuparse "de la satisfacción, aunque sea parcial, de esos derechos en las condiciones económicas de la actualidad”. Con ese liberalismo "así entendido", argumentaba Justo, los socialistas tenían "cierta afinidad”. Sin embargo, la delimitación política y organizativa debía ser clara: "miramos como un error o una mistificación”, concluía, "toda tentativa de confundirlo con el movimiento obrero. Que haya en buena hora centros liberales; pero no centros liberales de obreros" $\underline{25}$.

La intervención de Justo marcó así un salto en el debate. Reforzaba la línea argumentativa que venía presentando La Vanguardia -en el sentido de diferenciarse del movimiento anticlerical que estaba en cursopero lo hacía con mayor profundidad analítica. Su argumentación se enmarcaba en su formulación teóricopolítica más sofisticada y más general. Caracterizaba al liberalismo como un movimiento propio de la burguesía, al cual se le reconocía un carácter progresivo en el pasado, e incluso en el presente: según Justo, era posible coincidir en determinadas ocasiones con ese movimiento, con el objetivo de obtener ciertas reivindicaciones $\underline{\underline{26}}$. Pero lo fundamental era que la clase trabajadora debía organizarse en forma separada del liberalismo y de la burguesía, en torno a un proyecto socialista, que era entendido siempre en clave de “elevación material y moral”, gradual y progresiva, evolutiva y por tanto reformista, de los trabajadores y el pueblo. El hecho de que el propio Justo considerase necesario intervenir en el debate revela que advertía el potencial riesgo de un movimiento liberal de reformas sobre su proyecto político, por un lado, y también la competencia con una figura como Palacios, por el otro.

El 16 de noviembre volvió a intervenir Repetto/Publisher, en un artículo que reconocía en toda la línea la autoridad intelectual de Justo. El autor decía estar contento "de haber contribuido -con mi confusionismo- a que el compañero Dr. Justo escribiera su artículo sobre el tema”, en tanto ello había permitido poner "en claro y en su sitio muchas cosas que hemos estado mirando con cierta confusión”. Su artículo, en cualquier caso, volvía a colocarse en un plano menos elaborado de debate, e insistía en caracterizar a los círculos de obreros liberales como "sectas", en tanto eran agrupaciones organizadas en torno únicamente de un aspecto, en este caso la crítica a la religión. Repetto extraía una conclusión básica: la participación de trabajadores en este tipo de círculos tendría una consecuencia negativa, en tanto los alejaría del socialismo: “¿de qué sirve”, concluía, “que los obreros se cristalicen en el liberalismo si son incapaces de ser socialistas?” $\underline{7}$

Palacios buscó un compromiso: respondió que sus “sentimientos” habían sido “mal interpretados” y que no había querido responder al primer artículo de Publisher pero celebraba la intervención de Justo. Palacios evitaba así un choque con la figura más autorizada del partido, a quien decía no conocer personalmente pero sí respetar, porque "sé que tiene talento y que no es sectario". Agregaba que "al Dr. Justo se le conceptúa como un maestro y por ende su palabra tiene autoridad”. Su estrategia era presentar su postura como compatible con los señalamientos justistas: retomaba y se apoyaba para ello en el señalamiento de que los socialistas debían “mirar con simpatía los retoños liberales que están apareciendo en el país”. Luego de este intento de conciliación, de todos modos, Palacios reconocía que era notoria su participación en la fundación de círculos de obreros liberales y por ello creía necesario explicar su proceder. Señalaba que hasta el momento el movimiento socialista había avanzado muy lentamente mientras, al mismo tiempo, el clericalismo había advertido el peligro de las ideas socialistas y se había lanzado a crear los Círculos de 
Obreros Católicos, “de los cuales la República está plagada”. Ante este escenario, planteaba que su intención era encontrar la mejor táctica para "coadyuvar a que el socialismo marche con paso de gigante”. Con astucia, se amparaba en la cita de Justo según la cual el liberalismo era "precursor del socialismo" para argumentar que entonces el movimiento liberal podía actuar como estación intermedia necesaria para alejar a los obreros del clericalismo y acercarlos al socialismo. "La distancia que existe entre un círculo católico y un círculo socialista es mucho mayor que la que pueda existir entre aquel y un círculo de obreros liberales", argumentaba Palacios, intentando mostrar que se trataba de un recurso táctico: "no hagamos cuestión de palabras, me he dicho, fundemos los círculos liberales presentando el socorro mutuo y otras ventajas que presentan los católicos y conseguiremos desprender de los tentáculos del pulpo clerical a esa falange de desgraciados". Se presentaban ambas organizaciones como complementarias antes que contradictorias: "el Círculo de Obreros Liberales comenzará la obra, los Círculos Socialistas la completarán”. Concluía diciendo que creía "haber obrado como socialista convencido", pero al mismo tiempo se definía como "un hombre libre que marcha en pos de su ideal, sereno y con fe"료.

Pero la dirección partidaria no quería un compromiso sino llevar la polémica a fondo. La respuesta estuvo a cargo de Julio Árraga, quien cuestionó que Palacios no hubiera ofrecido ninguna razón para sustentar sus afirmaciones de que los centros liberales ayudarían a acercar a los obreros al socialismo. En su opinión, los círculos liberales no ofrecían nada muy distinto de los católicos: "médico, botica y un poco de música con algunas conferencias tendientes a neutralizar los efectos de la propaganda católica”. Para Árraga, lo esencial era que para un obrero resultaría más atractivo afiliarse al Partido Socialista, en tanto era "más factible convencer al obrero de que le conviene más incorporarse a un partido que está luchando y obteniendo mejoras (...) que demostrarle que le es más conveniente luchar por las ideas liberales que por las católicas”로. Coincidía con Justo en señalar que “el liberalismo podía aceptarse para luchar contra el catolicismo cuando el socialismo no había tomado los caracteres prácticos, concretos y de ventajas inmediatas que tiene en la actualidad”. Por otro lado, discrepaba con Palacios en cuanto a la debilidad del Partido Socialista: sostenía que el socialismo había crecido en forma considerable, y además que no debía incorporar en forma indiscriminada dado que era "un partido de principios", en el cual la afiliación requería un esfuerzo intelectual, y que debía mostrarse la diferencia con las fuerzas de la política criolla $\stackrel{30}{\text {. }}$

En cualquier caso, el propio Palacios también se mantenía firme en su postura. El 1 de diciembre se inauguró un círculo liberal en la parroquia del Pilar: en el acto inaugural habló el propio Palacios además de Cosme Mariño y otros. Según la crónica de La Constancia, una revista espiritista editada por el propio Mariño, la manifestación de "cerca de mil personas" se dirigió luego a dejar una corona en el monumento a Garibaldi, donde volvió a hacer uso de la palabra el joven abogado $\underline{31}$. Una semana más tarde, en una conferencia de Antonio Varela realizada en la Biblioteca Obrera acerca de "Socialismo y liberalismo", Palacios pidió la palabra, polemizó con el conferenciante, volvió a intentar apoyarse en los planteos de Justo, "que era su maestro”, y concluyó “diciendo que notaba que desde hace algún tiempo se le hacía una crítica persistente, tenaz; que ya no se atacaba al liberalismo sino al ciudadano Palacios”. El cierre fue turbulento: al bajar de la tribuna, Palacios se retiró en el momento en que Varela comenzaba a responder la última pregunta. Según $L a$ Vanguardia, "en ese momento los liberales que asistían a la controversia, como a una señal, se levantaron en masa, retirándose en una forma que traía a la memoria los regimientos, cuando marchan marcando el paso" $\underline{32}$.

\section{Del debate político al cuestionamiento disciplinario}

El episodio de la conferencia marcó una escalada del conflicto, que pasó de la discusión teórica a un 
cuestionamiento directo a Palacios y a su condición de militante. Fueron Repetto y Vidal, dos caracterizadas espadas del justismo, quienes reorientaron las líneas de la discusión, en La Vanguardia del 14 de diciembre. El primero de ellos publicó un artículo que reivindicaba como propias las notas firmadas por Publisher y destacaba que habían tenido el mérito de estimular la intervención de otros militantes en un asunto que “afecta los intereses del Partido Socialista”. Lejos del plano teórico en el que había sido colocado el debate por Justo, Repetto llevaba la discusión a un terreno disciplinario: lo que estaba en juego ahora era un juicio sobre las acciones de Palacios. "La creencia de que los círculos de obreros liberales servirán para desviar hacia el Partido Socialista la corriente de infelices que se dirige actualmente hacia los círculos católicos”, es decir, el argumento esbozado por Palacios en su intervención, era según el autor de la nota "una pamplina que no merece discutirse". "Lo importante”, argumentaba Repetto, era determinar "si un socialista consciente y afiliado al partido puede y debe consagrar una gran parte de sus energías a la fundación de sociedades obreras que no persiguen fines políticos ni gremiales”. En su opinión, no podía ni debía hacerlo. Repetto advertía que Palacios figuraba "en numerosas organizaciones y partidos liberales”, lo que obligaba al Partido Socialista a "invitarlo a que explique el carácter de las agrupaciones en que figura a fin de saber si goza de una doble ubicación política”글. Vidal, por su parte, denunciaba que el joven abogado había "usado y abusado del nombre del ilustrado compañero", en referencia a Justo, "presentándolo como indirecto auspiciador de su equivocado proyecto". Consideraba que Palacios decía conocer el socialismo pero que "sus actos como socialista est[aban] muy lejos de avenirse con aquel conocimiento". Concluía planteando que quería "llamar la atención de quien corresponda a fin de que el partido tome cartas en el asunto y marque la norma de conducta que en lo sucesivo debe seguir ante la actitud por todos conceptos censurable asumida por el Dr. Palacios” $\underline{34}$.

Recién el 21 de diciembre encontramos una postura favorable a Palacios, a través de una carta enviada por Antonio Mantecón, quien argumentaba que la pertenencia a un círculo liberal no causaba "un perjuicio para la marcha regular de nuestro partido, por la sencilla razón de que en esos círculos no se hace propaganda antisocialista, sino más bien se trata -aunque veladamente- de inculcar entre sus afiliados las ideas que nosotros sustentamos”. Mantecón defendía que los socialistas intervinieran en esos ámbitos y tocaba una cuerda sensible al recordar que nadie había presentado sus críticas cuando algunos socialistas se incorporaron a la masonería $\frac{35}{}$. El mismo día se publicó una nota del mismo Palacios, que caracterizaba las acusaciones de Repetto como "calumnias” y aclaraba que nunca había "militado en las filas de partidos personales" $\underline{36}$.

Pero una vez más quedaría en evidencia que la dirección partidaria y los editores del periódico no estaban interesados en un compromiso: en el número siguiente aparecieron nada menos que cuatro intervenciones sobre la cuestión, todas ellas contrarias a Palacios. J.B. Echeverría se ocupó de responder a Mantecón, señalando que el problema no era que Palacios hubiera participado en un centro liberal sino que tomaba la iniciativa de fundarlos. Esa diferencia explicaba que el partido no hubiera tomado medidas contra los “socialistas masones”, mientras que ahora correspondía hacerlo $\frac{37}{7}$. Enrique Dickmann, por su parte, señaló que Palacios estaba "acorralado en el campo de los argumentos, no pudiendo, ni sabiendo contestar a las múltiples y sólidas razones de los compañeros Justo, Árraga, Varela, Repetto y Vidal”, ante lo cual apelaba a "una argucia de mal abogado” y buscaba presentarse como una víctima. Dickmann apuntaba a los rasgos individualistas e indisciplinados de Palacios, algo que sería eje de la crítica del partido durante décadas: el problema, desde su perspectiva, era que Palacios carecía de "educación e instrucción socialista”, lo cual le impedía comprender que lo que estaba en juego no era "su sagrada e inviolable persona”, "ni sus intenciones que pueden ser tan puras como el mismo espíritu santo", ni tampoco "su credo liberal-espiritista inmaculado", sino el hecho de que su obra era "perniciosa”. Palacios se limitaba a victimizarse: Dickmann lo atribuía a una "herencia criolla" de la cual no había podido librarse aún. Concluía haciendo explícita la 
secuencia que había seguido Palacios, y mostraba hasta qué punto la dirección partidaria evidenciaba su preocupación ante un comportamiento que hasta el momento prefería mantenerse en cierta ambigüedad:

Empezó a pronunciar grandes discursos socialistas en locales y plazas públicas sin pertenecer a dicho partido; y cuando su posición se hizo insostenible en nuestro seno, fue a inscribirse en una agrupación de la provincia siendo habitante de la capital, y después de haber rodado por todos sus centros socialistas, en dos ocasiones desmintió públicamente la obra del congreso y del Comité Ejecutivo de nuestro partido; su principal actividad ha dedicado a los epílogos de Electra, a meetings contra el juego y otras cosas por el estilo; y por fin ha venido a rematar su obra en la fundación de ‘círculos de obreros liberales'. Ya es el colmo. $\underline{\underline{38}}$

El número incluía otra carta muy breve de Nicolás Repetto que hablaba del "carácter falso y calumnioso que se atribuye a mis afirmaciones", e insistía en que el partido debía "pronunciarse sobre este punto: ¿somos socialistas o liberales?”보. Por último, Luis Boffi opinaba que los círculos liberales eran "completamente inútiles" y que "la mejor propaganda anticlerical" era "convencer a los trabajadores de la necesidad de organizarse", recordando además que "cuando se trata del mejoramiento de la clase trabajadora, la gran mayoría de los liberales son tanto o más conservadores que los mismos clericales”. Boffi reclamaba que se diera por terminado el debate y se avanzara por las vías reglamentarias $\underline{40}$.

Efectivamente, ese fue el paso a seguir. En la primera semana de 1902 el comité ejecutivo convocó a un voto general "en que debe manifestar su opinión el Partido [sobre] la siguiente cuestión: ¿Puede un socialista militante organizar círculos de obreros liberales?” El voto general era la máxima instancia de dirección del partido: consistía en una convocatoria directa a todos los afiliados a emitir su opinión sobre una cuestión determinada. La dirección buscaba de este modo cerrar el debate con una demostración de fuerza que dejara clara a Palacios la necesidad de respetar la disciplina partidaria. Llevada la discusión a este terreno, el 18 de enero intervino por primera vez Alfredo Torcelli, dirigente del centro de La Plata al que pertenecía Palacios. El tono de su intervención ponía de relieve el alcance de la crisis: denunciaba lo irregular de la convocatoria al voto general, recordaba que en un primer momento el comité de La Plata se había mantenido "tranquilo" dado que "la cosa no valía la pena” y advertía, sin embargo, que luego "el acaloramiento en la discusión” había "degenerado la cosa hasta darle proporciones de diatriba”, hasta llegar a "una especie de atropello en que hasta se dejó embarcar el comité ejecutivo”. Para Torcelli, la convocatoria a un voto general era una medida irregular e inaceptable. En este marco, informaba, la agrupación de La Plata había resuelto "hacer presente al comité ejecutivo nacional que había visto con desagrado la intervención directa y no autorizada que tomaba contra uno de sus adherentes”, así como también pedir al comité ejecutivo que les informara cuáles eran las tres agrupaciones que habían pedido la convocatoria a voto general, tal como exigían los estatutos. Yendo a lo político, Torcelli se limitaba a plantear que no había "nada establecido que se oponga a que los miembros del partido puedan formar parte de las Logias masónicas o de los círculos liberales”쓰.

La dirección partidaria se mantuvo firme. La redacción de La Vanguardia publicó una pequeña respuesta, en la cual señalaba que disentía "por completo" con Torcelli, y que lamentaba el "exceso de vivacidad" en un compañero que, "por su ilustración, está en condiciones de mirar con más serenidad las pequeñas tormentas que agitan de vez en cuando a la familia socialista”. El mismo día se publicó además una respuesta del comité ejecutivo, firmada por Ángel Sesma, en la que se defendía el comportamiento del organismo dirigente del partido. Su argumento era que no podía considerarse autoritario "un comité que somete a la resolución del partido un asunto que puede ser de alta trascendencia para el porvenir del partido mismo”. Aclaraba que los estatutos debían servir como guía “pero en manera alguna cristalizan” la acción del partido $\stackrel{42}{\text {. }}$ 
La vía disciplinaria actuó, en los hechos, como cierre de la polémica: en los meses siguientes, el debate prácticamente desapareció del periódico. El voto general se mantuvo abierto durante un largo período, a pesar de lo cual la participación no fue demasiado elevada: el 10 de mayo se publicaron los resultados, que dieron un previsible triunfo a la respuesta negativa, 292 votos, contra la favorable, que alcanzó 69; con 29 abstenciones. La dirección se anotaba así un triunfo aunque con una participación relativamente baja y casi un $20 \%$ de votos que respaldaban a Palacios.

Hubo, en cualquier caso, un último coletazo de la polémica luego de una conferencia "liberal-socialista" organizada el 8 de junio de 1902 por el Centro Socialista Norte, a la cual fueron invitados miembros de los círculos de obreros liberales. Los oradores socialistas en esa ocasión fueron Varela y Repetto, indudables defensores de la línea de la dirección partidaria en este terreno: según las crónicas, Palacios volvió a intervenir durante el debate amparándose en las posiciones de Justo, lo cual dio lugar a una nueva intervención de este último el 21 de junio. La nota, enviada desde Junín, respondía a un pedido de la redacción del periódico que solicitaba la intervención de la más autorizada voz partidaria para dar un cierre a la discusión. En la presentación de la nota, de hecho, se señalaba que contribuiría "a ilustrar de manera concluyente sobre un asunto que debe quedar de hecho solucionado para siempre”. Justo advertía que Palacios citaba "opiniones mías en apoyo de su obra equívoca”, por lo cual "aceptaba gustoso la invitación" a aclarar la cuestión. El tono era inusualmente duro: señalaba que no era su culpa que Palacios intentara usar sus argumentos, y agregaba que no resultaba sorprendente viniendo de parte de alguien que decía "haber probado la existencia de vibraciones desconocidas porque no afectan nuestros sentidos”; según Justo, no era extraño que "quien es capaz de probar tan abstruso teorema teosófico lo sea también de sacar de mis opiniones argumentos inconcebibles para mí”.

Justo volvía a señalar que, en términos históricos, el liberalismo era "el precursor del socialismo, como la burguesía lo es del proletariado". Eso no implicaba, sin embargo, "deducir de ahí que es necesario titularse liberal para llegar a ser socialista", dado que ello sería lo mismo que "pretender que necesitamos primero ser burgueses para llegar a ser proletarios”. Ni siquiera para luchar por la libertad religiosa, agregaba Justo, necesitaba "el proletariado de una iniciación liberal": en este terreno, como en otros, el Partido Socialista tenía un programa "completo y radical" al respecto, y había "sostenido desde su origen la igualdad de todas las creencias ante la ley”. La clave era la "elevación de los trabajadores a los problemas políticos y sociales más complejos y difíciles”, pero para ello no era necesario desarrollar ningún tipo de educación liberal. Justo señalaba que podía comprender "que, en determinadas circunstancias, el movimiento obrero no pase de su forma gremial”, pero le parecía “absurdo intercalar en el desarrollo de la conciencia proletaria una fase liberal”.

Su conclusión era que Palacios debía definir su afiliación política, y dejaba incluso la puerta abierta a que se retirara del partido si no estaba dispuesto a aceptar su orientación:

Quiero creer al doctor Palacios sinceramente apasionado por los problemas morales y sociales que se refieren a las creencias. En este caso, debe entrar franca y resueltamente en las filas socialistas (...) Pero si no quiere confundirse demasiado en las filas, lo que, por supuesto, no siempre es agradable ni práctico, que organice otra fracción de la opinión con la cual tenga mayores afinidades, y así su acción también sería eficiente y plausible. Ni él, ni el movimiento obrero ganarán nada, en cambio, con la ambigüedad y la confusión. $\underline{43}$

Palacios respondió diciendo que no quería volver a la polémica, y que la "pretendida controversia liberalsocialista” había mostrado un "espectáculo triste”, pero se reafirmaba en sus posturas. Volvía a reivindicar las citas al artículo de Justo en términos generales, aunque aclaraba que mantenía su postura sobre los círculos liberales. "Sostuve y sostengo", señalaba Palacios, "que los círculos liberales de obreros son 
organizaciones de circunstancias que se adaptan perfectamente al ambiente de nuestra sociedad”. En defensa de esta interpretación informaba a Justo que "el círculo liberal de Palermo resolvió poco antes de ser llamado a la controversia pedir al C.E. del Partido Socialista que enviara un orador para que hiciera propaganda de sus ideas en el seno de esa agrupación” y también que el Círculo de Maldonado se había suscripto con acciones al proyecto de La Vanguardia diario. Intentaba una vez más marcar una diferencia entre Justo y el resto de la dirección, y concluía que le parecía "raro que este ciudadano, a quien conceptúo como un espíritu eminentemente científico, haga declaraciones como las que ha hecho, sin más fundamento que los diceres transmitidos por algún sectario" $\underline{4}$. Una semana más tarde, de todos modos, intervino Repetto para dar un cierre al debate, recordando que, en la controversia, "el socialista Palacios” había "defendido a los liberales" mientras reclamaba en su apoyo ideas de Justo. Con esta nota Repetto consideraba "cerrada para siempre la serie de mis escritos sobre este asunto", en tanto entendía que La Vanguardia merecía "más sustancia de la que contienen las colaboraciones en que no se habla sino del yo" $\underline{45}$.

\section{Conclusión}

El 2 de agosto de 1902 La Vanguardia publicó una editorial titulada “¿Dónde están los liberales?” que en buena medida resumía el cierre del ciclo abierto con las movilizaciones anticlericales de los años previos. Ya no se trataba de marcar las diferencias y delimitaciones con otros sectores que participaban en un movimiento anticlerical común: ahora se planteaba explícitamente el fracaso del liberalismo y su renuncia a desenvolver en forma consecuente la lucha contra la Iglesia y su influencia. Para La Vanguardia, la evidencia decisiva había sido provista por la incapacidad de los distintos sectores liberales de enfrentar de manera consistente la campaña clerical contra la ley de divorcio, una tarea que había quedado por lo tanto en manos de los socialistas. Los liberales, para el periódico, se limitaban a salir de su "letargo" una vez por año, para celebrar el aniversario de la república italiana el 20 de septiembre: eran incapaces por lo tanto de cualquier trabajo sistemático para enfrentar el avance clerical. Los socialistas debían congratularse de ser los únicos que merecían "de los reaccionarios de levita y de sotana los mayores ataques”, y felicitarse "de ser los únicos que sabemos combatir de veras a todos esos reaccionarios”. La conclusión era clara:

Despierten los trabajadores que pierden lastimosamente su tiempo vegetando en la masonería, las sociedades anticlericales y los centros liberales, despierten del error en que están y vengan a nuestras filas, que solamente desde ellas se puede combatir con éxito al oscurantismo, únicamente en ellas encontrarán campo fecundo para desenvolver su acción, horizontes para desarrollar sus energías y probabilidades de lograr sus legítimas aspiraciones de mejoramiento. $\underline{46}$

Si bien en esas mismas semanas, cuando finalmente se votó en el congreso la propuesta de ley de divorcio, los socialistas participaron como de costumbre en las manifestaciones callejeras y denunciaron frontalmente la presión clerical que llevó finalmente al rechazo del proyecto, la experiencia de casi dos años de debate y polémicas internas habían cristalizado una postura que subrayaba la necesidad de una delimitación política y organizativa con el resto del movimiento anticlerical y en particular con los sectores liberales. Un año más tarde, a mediados de 1903, el quinto congreso partidario sancionó estos planteamientos aprobando una resolución que establecía que la agitación anticlerical debía "ajustarse por completo a la táctica del partido y no a la estéril agitación liberal” (Oddone, 1983, p. 175).

En este trabajo hemos intentado mostrar cómo la delimitación de los socialistas con otros sectores del movimiento anticlerical en primer término, y la discusión con Alfredo Palacios acerca de la participación en los "círculos liberales de obreros" más tarde, articulan una serie de importantes problemas relacionados entre sí en la coyuntura de los años 1901 y 1902, y que se enmarcan por otra parte en discusiones que atravesaban 
en ese mismo período al conjunto de la socialdemocracia internacional. En primer término, hemos visto la cuestión de los vínculos que existían entre ciertos cuadros del socialismo argentino y el más amplio movimiento anticlerical que estaba en desarrollo en esos años; hemos visto que los vínculos eran fluidos y que el rol activo de los socialistas en las actividades de distintos grupos liberales -y en la masoneríaobligaban a una coexistencia constante que llevaba a tensiones y debates. En segundo lugar, de todos modos, se integra también en una problemática más general: el de la relación que debía existir entre el PS y otras fuerzas políticas consideradas "progresistas". A mediados de la década de 1890 se había planteado la discusión acerca de la relación que debía establecerse entre la militancia socialista y la UCR: la propia constitución del partido, en 1896, fue la expresión de cómo ese debate había sido saldado en favor de quienes argumentaban que los socialistas debían construir una organización independiente.

En este sentido, puede observarse el debate que tuvo lugar en 1901 y 1902 -que reconstruimos en este trabajo-, como un nuevo episodio de esta discusión, ahora no en relación con el radicalismo sino con el heterogéneo movimiento anticlerical y fuertemente influido por la aparición de un contradictorio personaje como Alfredo Palacios. Las tensiones que se venían acumulando desde 1900 en el marco de las movilizaciones anticlericales, y que se profundizaron con el carácter fuertemente indisciplinado que mostraba el joven abogado en su acercamiento al partido, estaban esperando una ocasión para decantar en una polémica abierta, que llegó con la cuestión de los círculos de obreros liberales. La aparición en escena de Palacios, una figura que se colocaba en el interior del partido pero ponía permanentemente en tensión las líneas establecidas por la dirección y comenzaba a consolidar una popularidad propia, alertó a la dirección socialista y en primer lugar a Juan B. Justo acerca de la necesidad de precisar la delimitación.

En efecto, la intervención sistemática de los principales cuadros de la dirección partidaria, y en particular la decisión del propio Justo de participar en el debate, dan cuenta de que era un tema que consideraban preocupante por las implicancias que podía tener para el futuro. Justo no podía dejar de advertir el desafío que representaba para su liderazgo una figura como Palacios, que no solo mostraba un carácter indisciplinado y personalista, sino también un vuelo intelectual propio y una interpretación del socialismo que ponía en tensión algunas de las caracterizaciones fundamentales del justismo. Si bien no lo mencionaba más que para un elogio lateral de sus notas enviadas desde Estados Unidos, "La miseria”, la tesis rechazada de Palacios, mostraba de hecho sustanciales diferencias con el pensamiento de Justo. Su eje era una denuncia del hambre y la miseria que insistía en que el desarrollo capitalista promovía legiones de hambrientos y desesperados. A diferencia de Justo, que explícitamente criticaba el elemento dialéctico en las obras de Marx, Palacios mostraba una mirada sombría sobre las consecuencias del progreso capitalista. "La causa del hambre”, argumentaba Palacios, “está en el sistema económico que nos rige, sistema funesto” (1988, p. 52). Al culminar el siglo XIX, el progreso y el desarrollo traían de la mano también un incremento de la desigualdad y la miseria: “donde quiera que aparezca el progreso, allí aparece el pauperismo”. Para Palacios, bajo el capitalismo "los ricos [eran] cada vez más ricos, los pobres cada vez más pobres” (1988, pp. 56, 58). El contraste con las posturas de Justo, para quien la tendencia de la sociedad capitalista era hacia el progreso y el desarrollo, era evidente.

Palacios era, en suma, un arma de doble filo para la dirección partidaria, ya desde estas fechas tempranas. Su incorporación al partido aportaba una personalidad destacada y popular, como se demostraría pocos años más tarde con la elección que lo consagró como diputado por la cuarta circunscripción de la capital, en 1904. Pero implicaba al mismo tiempo un desafío para la autoridad política de Justo y su equipo de dirección, que se apresuró a cerrar filas y poner un límite a los planteos de Palacios. Al hacerlo, reforzaban la necesidad de la construcción de un partido propio en las filas obreras y mostraban que, con todo lo que la "hipótesis de Justo" incluía de concesiones a una mirada liberal de la historia, en todo momento implicaba que la tarea de los socialistas era construir una organización propia, independiente incluso de los sectores progresistas de la 
burguesía. Esta era también la cuestión subyacente en la polémica, en tanto el carácter indisciplinado y el personalismo de Palacios daba lugar a una acción común con grupos liberales que ponía en riesgo la tarea decisiva de fisonomizar al PS en forma independiente, como el auténtico y progresista representante de la clase trabajadora.

\section{Notas}

1 El debate en torno a los círculos de obreros liberales ha permanecido virtualmente inexplorado en la historiografía dedicada a la historia del Partido Socialista. Sin dudas son los trabajos de Ricardo Martínez Mazzola los que más luz han echado sobre el vínculo del PS con otras fuerzas políticas en esta etapa: respecto a la cuestión de los círculos liberales, no obstante, el autor solo dedica una breve nota al pie en su tesis doctoral. Allí señala que era la tradicional desconfianza socialista hacia otras fuerzas políticas la que llevó a que "el socialismo mir[ase] con recelo y no otorg[ase] completo apoyo a la acción de grupos anticlericales y librepensadores, con los que tenía importantes coincidencias programáticas” (2008, p. 129).

$\underline{2}$ Protokoll des Parteitages der Sozialdemokratischen Partei Deutschlands: Abgehalten zu Erfurt vom 14. bis 20. Oktober 1891. Berlin, 1891, pp. 3-6.

$\underline{3}$ En los años inmediatamente posteriores al debate que reconstruimos en este trabajo, de hecho, tuvo lugar una extendida discusión de alcance internacional que se plasmó en una extensa "Enquête sur l'anticlericalisme et le socialisme”, publicada entre noviembre de 1902 y mayo de 1903 en la revista francesa Le Mouvement Socialiste. La encuesta reveló la diversa gama de abordajes respecto a la Iglesia y su influencia (y, por lo tanto, frente a los movimientos anticlericales) que existía al interior de la socialdemocracia internacional. La principal diferencia parecía darse entre los socialdemócratas alemanes, firmes defensores de los planteamientos de su programa de Erfurt y por lo tanto de considerar a la religión como un asunto privado, y los mucho más divididos socialistas franceses, que intervenían en un medio político complejo junto a numerosos grupos anticlericales de tradición radical, con los cuales estaba planteada la cuestión de una acción común. El debate, por supuesto, retomaba las discusiones que habían salido a la luz en torno al affaire Dreyfus. Ver Poulat (1960) y Arbeloa (1973) para un análisis de la encuesta y reproducciones de varias intervenciones. No hubo ninguna colaboración de socialistas argentinos.

4 Cartei, G. (5 de enero de 1901). La reacción clerical. La Vanguardia, p. 1.

ㅁ Ver La Vanguardia del 12 de enero y 8 de junio de 1901 y La Prensa del 12 de enero, 20 de marzo, 8 de junio y 16 de septiembre de 1901. Ver también Bertoni, 2009, p. 18.

6 Ver La Prensa, 30 de septiembre de 1901.

7 Sobre divorcio. (14 de julio de 1900). La Vanguardia, pp. 1-2.

$\underline{8}$ Vidal, B. (25 de mayo de 1901). Detractores del socialismo: el diputado Olivera. La Vanguardia, p. 1.

9 X.X. (24 de agosto de 1901). La cuestión religiosa. La Vanguardia, p.1.

10 Dagnino, E. (7 de septiembre de 1901). El peligro clerical. La Vanguardia, p. 1.

11 Domenech, J. (14 de septiembre de 1901). Una buena idea y un mal manifiesto. La Vanguardia, p. 2.

12 Cartei, G. (21 de septiembre de 1901). Anticlericalismo utópico y anticlericalismo científico. La Vanguardia, p. 1.

13 Sesma, A. (5 de octubre de 1901). Lo del domingo. La Vanguardia, p. 1. 
14 Cartei, G. (5 de octubre de 1901). Desmanes. La Vanguardia, p. 2.

15 Cartei, G. (5 de octubre de 1901). Desmanes. La Vanguardia, p. 2. Ver los paralelismos con la delimitación que los socialistas realizaban con los anarquistas en este mismo período, en referencia a la posición a adoptar ante las huelgas (Poy, 2015).

$\underline{16}$ Conferencias realizadas: la del Dr. Alfredo Palacios. (25 de agosto de 1900). La Vanguardia, p. 2.

17 Ver La Vanguardia del 6 de octubre y 15 de diciembre de 1900.

18 Conferencias realizadas (24 de agosto de 1901). La Vanguardia, pp. 2-3.

19 Bosio, B. (12 de octubre de 1901). En defensa de la ciencia y de la táctica socialista. La Vanguardia, p. 2.

$\underline{20}$ Palacios, A. (19 de octubre de 1901). Ciencia y Religión. Con motivo de la conferencia del 6 de octubre. La Vanguardia, p. 2.

21 Palacios, A. (11 de enero de 1902). Círculos de obreros liberales. La Vanguardia, p. 2.

22 Publisher (26 de octubre de 1901). Deplorable. La Vanguardia, p.1.

$\underline{23}$ Justo, J. B. (9 de noviembre de 1901). Socialismo y liberalismo. La Vanguardia, p. 1.

$\underline{24}$ En este punto, Justo seguía la misma lógica que lo había llevado a rechazar la resolución del primer congreso partidario, en 1896, que prohibía las alianzas con otras fuerzas políticas. Justo argumentó en contra de esta medida y logró revertirla en el segundo congreso, celebrado en 1898. Esta posición favorable a dejar abierta la posibilidad de alianzas en general no era, en la perspectiva de Justo, contradictoria con su insistencia por delimitar al Partido Socialista respecto de las demás fuerzas políticas, carentes de programa, que existían en la Argentina del período. Antes bien, obedecía a un rechazo hacia disposiciones estatutarias estrictas que consideraba inútiles en el presente y problemáticas para el futuro.

$\underline{25}$ Justo, J. B. (9 de noviembre de 1901). Socialismo y liberalismo. La Vanguardia, p. 1.

$\underline{26}$ Tal como señala Ricardo Martínez Mazzola en un importante trabajo que contextualiza las lecturas del liberalismo hechas por el socialismo argentino en distintos períodos, "Justo no valoraba al liberalismo como una ideología humana y racional ni tampoco como la verdadera tradición argentina, sino como la cosmovisión que acompañaba los intereses de una clase, la burguesa” (2011, p. 39).

27 Publisher (16 de noviembre de 1901). Socialismo y liberalismo. La Vanguardia, p. 1.

$\underline{28}$ Palacios, A. (23 de noviembre de 1901). Socialismo y liberalismo. La Vanguardia, p. 1.

$\underline{29}$ Su argumentación, por otra parte, presentaba una interesante prefiguración de sus planteos sindicalistas: sostenía que las dificultades para incorporar a los obreros respondían a que se les planteaba "que el socialismo viene a cambiar la sociedad capitalista actual y a reemplazarla por otra más justa y más libre” en lugar de concentrarse "en el programa mínimo, cuyas declaraciones claras, concretas, están a su alcance”.

30 Árraga, J. (30 de noviembre de 1901). Socialismo y no liberalismo. La Vanguardia, pp. 1-2.

$\underline{31}$ Notas de la redacción (8 de diciembre de 1901). La Constancia, p. 1.

$\underline{32}$ Conferencias a favor de la biblioteca obrera. (14 de diciembre de 1901). La Vanguardia, p. 2.

33 Repetto, N. (14 de diciembre de 1901). ¿Centros socialistas o centros liberales? La Vanguardia, pp. 1-2.

34 Vidal, B. (14 de diciembre de 1901). Las cosas en su lugar. La Vanguardia, p. 2. 
35 Mantecón, A. (21 de diciembre de 1901). Futilezas. La Vanguardia, 21/12/1901. Está documentada la pertenencia de varios cuadros socialistas a la masonería en este período, entre ellos Roberto Payró (iniciado en 1887), Carlos Malagarriga (1897), José Ingenieros (1898) y Leopoldo Lugones (1899). Adrián Patroni se incorporó en agosto de 1900 a la Logia Estrella del Oriente, una asociación que tenía una conspicua presencia de socialistas: también pertenecía a ella Ángel Sesma, incorporado en 1902; Víctor García Costa menciona también a Ernesto de la Cárcova, Francisco Cúneo y Domingo Risso. El 15 de marzo de 1902 La Vanguardia saludaba la aparición de Res non verba, "periódico publicado por miembros de la Logia Estrella del Oriente" que "ha venido a la palestra con programa e ideas reformadoras", deseando "que su influencia se extienda y conmueva la dormida conciencia del mundo masónico". Alfredo Palacios se inició en 1901 en la Logia Libertad y al año siguiente fue uno de los fundadores de la Logia Justicia, que presidió en 19031904. Ni Juan B. Justo ni ningún otro miembro del ala porteña de su familia pertenecían a la masonería, a diferencia de lo que ocurría con la rama entrerriana, de la que era oriundo el futuro presidente de facto Agustín P. Justo (Lappas, 1966).

36 Palacios, A. (21 de diciembre de 1901). Carta de lectores. La Vanguardia, p. 3.

37 Echeverría J. (28 de diciembre de 1901). Futilezas. La Vanguardia, p. 3.

$\underline{38}$ Dickmann, E. (28 de diciembre de 1901). Escapando por la tangente. La Vanguardia, p. 3.

39 Repetto, N. (28 de diciembre de 1901). Carta de lectores. La Vanguardia, p. 3.

40 Boffi, L. (28 de diciembre de 1901). Terminemos. La Vanguardia, p. 3.

41 Torcelli, A. (18 de enero de 1902). El voto general ante los estatutos del partido. La Vanguardia, p. 1.

$\underline{42}$ Sesma, A. (18 de enero de 1902). El comité ejecutivo del partido y el voto general. La Vanguardia, p. 1.

$4 \underline{3}$ Justo, J. B. (21 de junio de 1902). Una opinión autorizada. La Vanguardia, p. 2.

44 Palacios, A. (5 de julio de 1902). Una aclaración. La Vanguardia, p. 2.

$\underline{45}$ Repetto, N. (12 de julio de 1902). Para aclarar una aclaración. La Vanguardia, p. 2.

$\underline{46}$ ¿Dónde están los liberales? (2 de agosto de 1902). La Vanguardia, p. 1.

\section{Bibliografía}

Arbeloa, V. (1973). Socialismo y anticlericalismo. Madrid: Taurus.

Bertoni, L. (2009). ¿Estado confesional o estado laico? La disputa entre librepensadores y católicos en el cambio del siglo XIX al XX. En L. Bertoni y L. de Privitellio (comp.), Conflictos en Democracia. La vida política argentina entre dos siglos (pp. 45-70). Buenos Aires: Siglo XXI.

Castro, M. O. (2012). El ocaso de la república oligárquica: poder, política y reforma electoral, 1898-1912. Buenos Aires: Edhasa.

Di Stefano, R. (2010). Ovejas negras: historia de los anticlericales argentinos. Buenos Aires: Sudamericana.

Freidenraij, C. (2011). Del Asilo a la Cárcel. Crisis y reconstitución del primer reformatorio argentino (fines del siglo XIX - principios del siglo XX). Ponencia presentada en las Terceras Jornadas Nacionales de Historia Social, La Falda, Córdoba, Argentina.

García Costa, V. (1997). Alfredo Palacios, entre el clavel y la espada. Una biografía. Buenos Aires: Planeta. 
Korzeniewicz, R. (1989). Labor Unrest in Argentina, 1887-1907. Latin American Research Review, 24(3), 71-98.

Lappas, A. (1966). La masonería argentina a través de sus hombres. Buenos Aires.

Marotta, S. (1960). El movimiento sindical argentino. Su génesis y desarrollo. Buenos Aires: Lacio.

Martínez Mazzola, R. (2008). El partido socialista y sus interpretaciones del radicalismo argentino (18901930) (Tesis doctoral), Universidad de Buenos Aires, Argentina.

Martínez Mazzola, R. (2011). Justo, Korn, Ghioldi. El Partido Socialista y la tradición liberal. Papeles de Trabajo, 5(8), 35-52

Mollès, D. (2012). ¿Derecha o izquierda? El anticlericalismo argentino frente a la cuestión social (19041910). Travesía, 14-15, 249-276.

Oddone, J. (1983). Historia del socialismo argentino. Buenos Aires: Centro Editor de América Latina.

Oved, I. (1976). El trasfondo histórico de la ley 4144, de Residencia. Desarrollo Económico. Revista de Ciencias Sociales, 61, 123-150.

Palacios, A. (1988). La miseria en la República Argentina. Buenos Aires: Centro Editor de América Latina.

Poulat, E. (1960). Socialisme et anticléricalisme. Une enquête socialiste internationale (1902-1903). Archives de sociologie des religions, 10(1), 109-131.

Poy, Lucas (2015). El Partido Socialista y las huelgas: una relación incómoda. Un análisis de las posiciones partidarias en los primeros años del siglo XX. Archivos de historia del movimiento obrero y la izquierda. 3(6), 31-51.

Rock, D. (2006). La construcción del estado y los movimientos políticos en la Argentina, 1860-1916. Buenos Aires: Prometeo.

Rojkind, I. (2006). Prensa, manifestaciones y oposición política. La protesta contra la unificación de la deuda en julio de 1901. Estudios Sociales. Revista universitaria semestral, 31, 137-162. 